\title{
Puzzles of insurance demand and its biases: A survey on the role of behavioural biases and financial literacy on insurance demand
}

Citation for published version (APA):

Pitthan, F., \& De Witte, K. (2021). Puzzles of insurance demand and its biases: A survey on the role of behavioural biases and financial literacy on insurance demand. Journal of Behavioral and Experimental Finance, 30, [100471]. https://doi.org/10.1016/j.jbef.2021.100471

Document status and date:

Published: 01/06/2021

DOI:

10.1016/j.jbef.2021.100471

Document Version:

Publisher's PDF, also known as Version of record

Document license:

Taverne

Please check the document version of this publication:

- A submitted manuscript is the version of the article upon submission and before peer-review. There can be important differences between the submitted version and the official published version of record.

People interested in the research are advised to contact the author for the final version of the publication, or visit the DOI to the publisher's website.

- The final author version and the galley proof are versions of the publication after peer review.

- The final published version features the final layout of the paper including the volume, issue and page numbers.

Link to publication

\footnotetext{
General rights rights.

- You may freely distribute the URL identifying the publication in the public portal. please follow below link for the End User Agreement:

www.umlib.nl/taverne-license

Take down policy

If you believe that this document breaches copyright please contact us at:

repository@maastrichtuniversity.nl

providing details and we will investigate your claim.
}

Copyright and moral rights for the publications made accessible in the public portal are retained by the authors and/or other copyright owners and it is a condition of accessing publications that users recognise and abide by the legal requirements associated with these

- Users may download and print one copy of any publication from the public portal for the purpose of private study or research.

- You may not further distribute the material or use it for any profit-making activity or commercial gain

If the publication is distributed under the terms of Article $25 \mathrm{fa}$ of the Dutch Copyright Act, indicated by the "Taverne" license above, 
Review article

\title{
Puzzles of insurance demand and its biases: A survey on the role of behavioural biases and financial literacy on insurance demand
}

\author{
Francisco Pitthan ${ }^{\mathrm{a}, *}$, Kristof De Witte ${ }^{\mathrm{a}, \mathrm{b}}$ \\ a Leuven Economics of Education Research, KU Leuven, Naamsestraat 69, 3000, Leuven, Belgium \\ ${ }^{\mathrm{b}}$ UNU-Merit, Boschstraat 24, 6211 Maastricht, The Netherlands
}

\section{A R T I C L E I N F O}

\section{Article history:}

Received 22 January 2021

Accepted 5 February 2021

Available online 9 February 2021

JEL classification:
G41
D80
D91
I22
G22
G53
Keywords:
Insurance demand
Underinsurance
Behavioural finance
Financial literacy

\begin{abstract}
A B S T R A C T
This paper reviews the puzzles of insurance demand, and provides an overview of behaviouralbased explanations on the concept of underinsurance. In particular, the study outlines the biases (among myopia, narrow framing and others) that help to explain the existence of those puzzles. The results indicate that biases do motivate the chances of underinsurance through sub-optimal probability weighting or wrong probability estimation of risks. We discuss that the literature has fallen short in providing possible solutions for the puzzles, with this study proposing financial literacy treatments, that aim at improving knowledge and use of finance, as a systematic solution.
\end{abstract}

(c) 2021 Elsevier B.V. All rights reserved.

\section{Contents}

1. Introduction

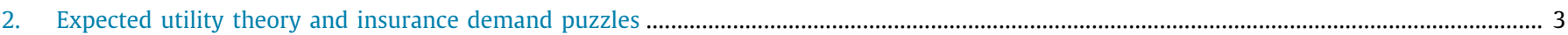

3. Explaining insurance for irrational agents - The biases of insurance demand................................................................................................ 3

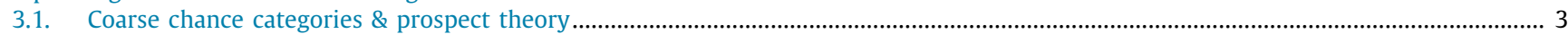

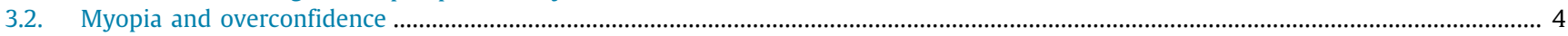

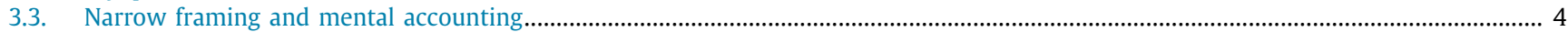

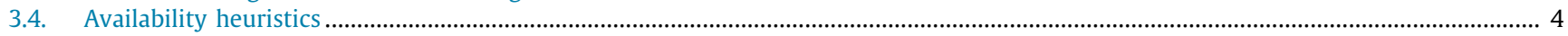

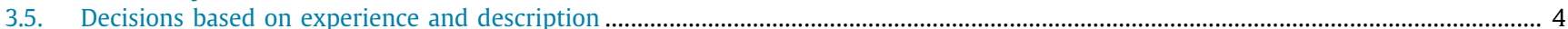

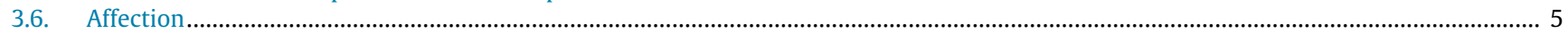

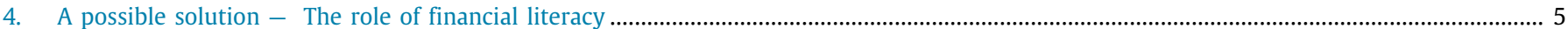

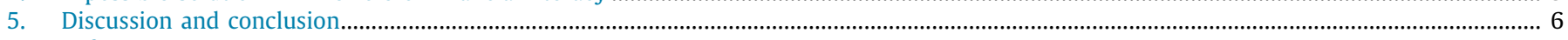

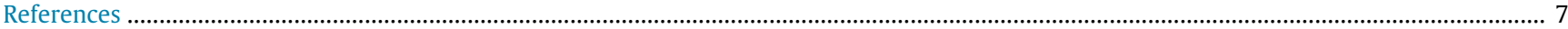

This work was supported by Baloise Insurance through the Research Chair to Financial Well-Being and by Fonds Wetenschappelijk Onderzoek Vlaanderen (FWO) under grant number 11K4621N. We would like to thank Charlotte Van Tiggelen, Geert Ghyssaert, Kenneth De Beckker, participants at the 'Conference on Financial literacy' and LEER seminar (KU Leuven).

* Corresponding author.

E-mail addresses: francisco.donascimentopitthan@kuleuven.be (F. Pitthan), kristof.dewitte@kuleuven.be (K. De Witte).

\section{Introduction}

One of the intriguing puzzles in the economics of insurance literature is the underinsurance of risks with high consequences (Kunreuther et al., 2013). This underinsurance creates a strong social problem, as yearly and in many parts of the world, considerable losses hit humanity in the form of natural disasters, diseases, incapacities, terrorism, pandemics and accidents, which can be extremely costly, especially to developing countries (Heger et al., 2008). Reviewing similar puzzles of insurance demand, the 
present paper provides an overview of behavioural-economics based explanations on the concept of underinsurance. In addition, the study discusses possible solutions for the insurance puzzles and aims at exploring the role of financial literacy in the underinsurance of risks with high consequences.

Loss aversion is a compelling argument of how insurance can provide a welfare improvement for people, since the payment of an actuarial-fair premium (or a premium that is at least below the certainty-equivalent) to get fully insured against a loss is a utility improvement for loss-averse people. Loss aversion was introduced by Tversky and Kahneman (1979), where it was shown that people tend to prefer the avoidance of losses rather than the realization of a gain of the same amount. Booij and Van de Kuilen (2009) show evidence that it prevails in broader society.

In the insurance literature, the risky events that need insurance are usually categorized according to the degree of consequence and probability. For a few examples, natural disasters would be considered as low-probability high-consequence (LPHC) risks; bike thefts would be high-probability low-consequence (HPLC) risks; while health issues would be high-probability highconsequence (HPHC) risks. By the expected utility theory, insurance for high-consequence risks would be preferred face to low-consequence risks (even for the same expected loss), but this is not what was verified in the literature, with the demand for high-probability and low-consequence risk being comparatively higher to low-probability high-consequence risks (Browne et al., $2015)^{1}$, what gives rise to the insurance demand puzzles. However, despite the argument of loss aversion and of the expected utility theory, the study observes that many people are still uninsured in many dimensions, especially for high-consequence risks.

Since this underinsurance is also observed in countries with well-developed insurance markets (sometimes with subsidized premiums), this problem cannot be fully explained by undersupply of insurance (Kunreuther et al., 2013). Thus, the insurance demand literature focused on searching for explanations of the insurance puzzles using insights from behavioural economics. The basic idea consists in the effects of biases and heuristics in the probability estimation and weighting of risks, which result in suboptimal insurance decisions. Among the biases and heuristics that affect insurance demand, we distinguish between coarse chance categories (i.e., direct application of prospect theory, with huge boosts in probability weighting when consumers see a risk as possible or as certain); myopia (i.e., underestimation and underweighting of average probability due to few information and focus on surroundings); overconfidence (i.e., underweighting and underestimation of idiosyncratic probability, but right estimation of average probability); narrow framing and mental accounting (i.e., failure to consider interactions among decisions in different mental frameworks, sometimes also fail to account for iterations of the same event across time); availability heuristics (i.e., more importance to events that come easily to mind, due to recent or vivid memories); decisions based on experience and description (i.e., more weight to information received via external description in comparison to information based in life-experiences, which sometimes have a small sample); and affection (i.e., more weight to insure against losing objects with emotional attachment).

Although the insurance literature proposed many behaviouralbased explanations for the demand puzzles, it still did not propose compelling solutions for those problems. Burns et al. (2010) propose the idea of giving the right and specific "remedy" to the main "symptom" of each one of the different biases, but with

1 Using data from an insurance firm in Germany, Browne et al. (2015) found that only $13 \%$ of insurance policy owners had protection against natural hazards insurance, with the demand for bike theft insurance being greater. no widespread solution, since each bias would require different treatments. If we consider the biases and heuristics that affect insurance, most of them are motivated by a lack of knowledge or misuse of financial concepts and products, which can be directly linked to low levels of financial literacy. The role of financial literacy, which combines knowledge, attitudes, and skills to guarantee financial decisions that promote better financial well-being, is wrongly neglected as one of the main possible drivers and paths to mitigate the impact of behavioural biases in insurance decision making. Treatments of financial illiteracy through education or advisory were found to be particularly beneficial to improve insurance demand in communities suffering from underinsurance (Cole et al., 2013), yet, rarely any studies have focused on analysing the impact of improving financial literacy to reduce the effects of behavioural biases and heuristics in insurance demand.

This paper contributes to the literature in two distinct ways. First, it links the main puzzles of insurance demand to behavioural biases. As such, using insights from behavioural economics, we provide an explanation of these puzzles. Second, the study discusses the role of financial literacy in the inconsistencies in insurance demand. This will be conducive to addressing the gap present in the existing literature concerning possible solutions to the biases of insurance demand.

Other surveys also focused directly or indirectly on behavioural biases effects into insurance demand, however, the current paper differs in its approach and objectives. Besides reviewing the insurance puzzles, the effect of biases, and heuristics in insurance demand, the study also focuses on discussing possible solutions to mitigate the behavioural problems that lead to suboptimal insurance levels. In addition to these different approaches, the paper is different from Barberis (2013) in the way that the current study focuses more explicitly on the concept of insurance demand and some risks with high probability. The objective of the research framework is distinct from that of Richter et al. (2014), in the way that their study was solely based on the theoretical implications and while the current study focuses on a broader set of papers (they focus mainly on four papers from the same journal special edition). Although Harrison and Ng (2019) review many current papers of insurance demand, they do not focus in the role of behavioural biases nor the possible financial literacy ${ }^{2}$ and cognitive gaps which could explain insurance puzzles, instead, they discuss the different experimental and insurance decision settings with a theoretical motivation.

The current study follows the methodology suggested by Higgins and Green (2011), with the papers being selected based on three comprehensive steps. First, the study began with searching in the Web of Science and ERIC web directories among titles, abstracts and keywords for the research terms related to insurance demand, behavioural biases, and financial literacy, using Booleans to find interactions between works of literature. Second, the selected papers' abstracts were screened and their titles were closely observed. This was done in order to ensure that the present does not deviate from its pre-defined set of objectives. Thirdly, to search for extra references, Web of Science and Google Scholar were used to check in the selected papers their citations and research that cited them. This approach led to 465 references, which using our selection steps resulted in 71 works.

The findings of the paper can be summarized as follows: although behavioural biases can explain the puzzles, the way to solve this demand problem is not necessarily through the

\footnotetext{
2 They make one mention to Clarke and Kalani (2012) which, among other objectives, checked the relationship of microinsurance demand with financial literacy. But we find that their measure of financial literacy was more related to numeracy (only one of their eight questions was related directly to financial knowledge or behaviour).
} 
behavioural literature, since no general solution was found, requiring different treatments for different biases. Beyond the most direct way of treating the puzzles by solving disinformation or by giving the proper "remedy" to each bias, the possible solution through the financial literacy approach might be a more broad and systematic direction, going in the root causes of most biases, with the possibility to apply financial literacy's educational and advisory methods in multiple environments.

The current paper unfolds as follows. Section 2 of this paper discusses the insurance decision-making under expected utility theory, and its contradiction over the puzzles of insurance demand. Further, Section 3 discusses the main behavioural-based explanations for the insurance demand puzzles. In Section 4, the role of financial literacy in insurance demand and its biases is discussed. Lastly, Section 5 provides the conclusion of the entire study.

\section{Expected utility theory and insurance demand puzzles}

Barberis (2013) points the over and under assessment of probability estimations and weights as one of the main motivations for the existence of antagonistic outcomes in the decision making of tail events. ${ }^{3}$ This can be explained by different preferences but can also be heavily impacted by beliefs, heuristics and behavioural biases. As insurance demand is within the same framework of decision making, it is also affected by different outcomes, causing underinsurance of some risks and over-insurance of others. This makes the appearance of some puzzles in insurance demand, in the way results from the empirical and experimental literature differ from the economic theory. One of them is the low insurance demand for LPHC risk in comparison to the high insurance demand for HPLC risk, that can also be motivated by biases. Seeing the great life-cycle welfare improvement of insurance against rare events with significant impact (e.g. disaster like flood, fire and earthquake) for risk-averse individuals, it is puzzling why the demand for LPHC risk insurance is so low in comparison to the one for HPLC risk insurance.

Concerning the view of the economic theory for the insurance demand of different risks, the expected utility theory proposes that risk-averse individuals faced with the decision to get insurance against one of two risks $A$ and $B$ with the same expected loss, but where $B$ has a higher variance, shall prefer to insure against risk B (Browne et al., 2015). They discussed that the puzzle lies in the contradiction of the outputs from the theory and the results from the literature since this is often not the case in experiments and empirical data of insurance demand. Under the same expected loss and the same expense-loading in the premium, the demand for insurance against HPLC risks (equivalent to risk $\mathrm{A}$ ) is greater than the one for $\mathrm{LPHC}$ risk (equivalent to risk B), which would contradict the expected utility theory, as seen from experiments of Slovic et al. (1977); Ganderton et al. (2000) and empirical study of Browne et al. (2015). Laury et al. (2009) replicates the experiment of Slovic et al. (1977) but using real money, arguing that previous results were due to the presence of confounds in the experiments, which may still be considered with care, because they diverge from the rest of the literature of experimental and empirical data.

Additionally, consider still the possible risk $\mathrm{C}$, which would have the same variance of risk $A$, but a higher average loss associated (i.e. a case of an HPHC risk). Using the expected utility theory approach, individuals should also prefer to insure against risk $C$ in comparison to risk A. Considering that most HPHC have mature markets this is often the case, but still the study also

\footnotetext{
3 Within an insurance framework, an example would be the decision to buy insurance for events with LPHC risks (e.g. natural disasters).
}

observes exceptions, like the low demand for long-term care (LTC) insurance.

Since one of the main hypotheses of the expected utility theory is the rationality of individuals, the recent insurance demand literature has taken the behavioural and cognitive approach in order to search for reasonable explanations for these puzzles in insurance (i.e. underinsurance of LPHC risks, over-insurance of HPLC risks and underinsurance for some HPHC risks such as LTC). This literature is based on theoretical, experimental and empirical evidence that finds the explanation to this over or underinsurance of different risks based on the existence of at least part of the market that suffers from behavioural biases or that use heuristics during their decision-making process. The next chapter explores the main developments of the behavioural biases of insurance demand literature.

\section{Explaining insurance for irrational agents - The biases of insurance demand}

This section investigates the main biases and heuristics that govern the insurance decision-making. The behavioural biases are chosen for their prominence in the literature to explain the over and underinsurance of different risks, based on their impact in either the probability estimation or probability weighting of people's insurance decision making. Although other biases than the discussed ones exist in the behavioural finance and decision-making literature, they are not sufficiently relevant in the insurance demand literature to explain insurance puzzles.

\subsection{Coarse chance categories $\mathcal{E}$ prospect theory}

Tversky and Kahneman (1992) proposed the cumulative prospect theory, that showed experimentally the existence of an S-shaped probability weighting function. This was done to weight probabilities in the decision-making process under uncertainty, which was conducive to explain the overweight of small probabilities and underweight of high probabilities. However, they found that this function is not well behaved near end-points, especially for really small probabilities, which could be either completely ignored or extremely overweight.

The bad-behaviour of the probability weighting function can be related by coarse chance categories and the "possibility-effect" Burns et al. (2010), which comes as a direct result from prospect theory. Piaget and Inhelder (1951) related the perception of chance and probabilities by children, which corresponded to categories of (e.g. "it certainly won't happen", "it may happen”) not that different from how adults may interpret uncertainty events and their poor understanding of probabilities (Reyna and Brainerd, 2008). For instance, an event can have its label changed from "it certainly won't happen" to the label "it may happen", the so-called "possibility-effect", increasing drastically the weighting of this probability in the decision making of an individual. While small changes of probabilities that may lead to change the label of an event from "it may happen" to "it certainly will happen" can also have a significant effect (the "certaintyeffect"), small differences in intermediate probabilities might be understood as insignificant, as seen in the experiments of Tversky and Kahneman (1992).

Schmidt (2016) comes with a theoretical approach to the role of prospect theory in insurance demand, showing that it is sufficient to explain that low insurance demand for low probability risks (even with highly subsidized premiums) may face the high insurance demand for moderate or high probability risks (even with highly loaded premiums). Using American data, Hwang (2016) empirically found that loss-averse individuals have lowownership of LTC insurance, which is consistent with prospect 
theory when individuals' have reference points for wealth levels. This is the case when they do not engage in insurance contracts and view insurance premiums as risky assets (i.e. generates no "return" in case of the insured bad event does not happen).

\subsection{Myopia and overconfidence}

The biases of myopia and overconfidence are related to the under-estimation and under-weighting of bad outcomes. As noted by De Donder and Leroux (2013), they differ in the way the estimations are formed. Overconfident individuals have a good estimation of the average probability of loss for a given risk, but usually decide to not insure themselves because they are of the view that they have a lower probability (and lower confidence intervals) than the average of being affected, underweighting this risk in their decision making. On the other hand, myopic people, besides this underweighting, also underestimate the average probability of a bad outcome for a given risk. Myopia is also related to the preference for short-term benefits and for decisions that are closely related to their environment (either spatially, temporally, or emotionally), as seen in Maskell and Malmberg (2007) and Kunreuther et al. (2013). Nonetheless, myopic and overconfident individuals do not usually differ in their decisions, but differ in their thought process.

Earlier literature found evidence on the existence of myopia and overconfidence in insurance. De Donder and Leroux (2013) found that the decision to not buy LTC insurance is compatible with overconfident and myopic individuals, but not with procrastinators. Cremer and Roeder (2013) justify the social provision of public LTC risk insurance or the subsidize of private insurance with a model that considers myopia and actuarially non-fare loading-costs. Galle (2012) shows through a model that decisions benefiting public unemployment insurance are wounded by myopia, and that immediate incentive could make those decisions more common.

\subsection{Narrow framing and mental accounting}

Narrow framing (Tversky and Kahneman, 1981) is a direct application of prospect theory, a bias heavily influenced by framing (i.e. how problems, choices. and data are presented), that suggests that individuals usually are more sensitive to negative frames than positive ones. ${ }^{4}$ Also, as a consequence of this sensitivity to framing, each decision or gamble is evaluated individually, in isolation from future opportunities, also neglecting other possible frames and the statistics of the past in evaluating current plans. For instance, many individuals under narrow framing faced with Samuelson's (1963) bet (50\% chance of winning \$200 against 50\% chance of losing \$100) would not accept it even when faced with multiple repetitions of the same bet. Brown et al. (2008) also suggests that framing matters for how to consider insurance annuities, either as a consumption (valuable insurance) or as an investment (a risky asset with payoffs in case of bad outcome), with individuals under the investment frame preferring nonannuitized insurance products. Using the prospect theory as its basis, Thaler (1985) reports that mental accounting consists of the idea that decisions are framed inside different "accounts" without considering interactions among multiple decisions or multiple "accounts". Mental accounting is also subject to framing, but in more general terms, since different decisions can be inside the same "account". He suggests an application of this bias to

\footnotetext{
4 For example, Tversky and Kahneman (1986) show that people would be more impacted by a risk showing statistics that 10 out of 100 people, the "mortality frame" rather than saying that 90 out of 100 survived, "the survival frame".
}

"add-ons" in big insurance policies. As that would be calculated inside the same account, individuals would consider them as a smaller-loss in comparison to buying them separately (e.g. a $\$ 5$ premium increase to have dental insurance to an already existing $\$ 50$ health insurance premium would seem more reasonable than a non-bundled $\$ 5$ dental insurance under this bias).

Hsee and Kunreuther (2000) experimentally found that, depending on different frameworks and perception of gambles and accounts, the same monetary loss could have a different perceived value and individuals would be more willing to buy insurance. In contrast to this, Schwarcz (2010) argues that the mental-accounting bias helps to explain the high demand for insurances against small financial losses (e.g. bike theft), which would not be rationally related to the individual's full wealth, but considering separately into a different "account" would be reasonable for the individual. Empirical data of Gottlieb and Mitchell (2019) suggest that individuals under narrow framing are less likely to insure themselves against LTC risk. This is because such individuals might fail to "evaluate the potential benefits of avoiding the losses alongside the costs of insurance", and thereby, being less eager to buy insurance.

\subsection{Availability heuristics}

The availability heuristics are based on Tversky and Kahneman (1973), who proposed a concept about the assessment of the probability of an event by the "(...) ease which instances or occurrences can be brought to mind". Barberis (2013) notes that these heuristics can be explained as the overestimation of probabilities for events with vivid impact, either because it triggered some emotions or it had extensive media coverage. Moreover, it also explained the underestimation of probabilities for events with not such vivid images.

Keller et al. (2006) found experimental evidence on the role of availability for the perception of risk in flood areas when partial insurance was available, subjects that received the communication of past events in the area (frequencies, probabilities and photographs) had a greater perception of risk compared to control groups. Yin et al. (2016) portrayed through his study that after a first experience with a typhoon, individuals' demand is largely dominated by availability and so were more likely to insure against typhoon risk in the short-run, but if they experience a disaster multiple times the "gambler's fallacy" (Croson and Sundali, 2005) would dominate, which would result them in thinking that another typhoon would be less common.

\subsection{Decisions based on experience and description}

Hertwig et al. (2004) proposed and tested experimentally the idea, that, during decision making process, people usually overweight probabilities of rare events based on description available to them (e.g. when people have access to information sources with good descriptions of risks such as a book, a newspaper, television show) and underweight probabilities of rare events based on their experiences (e.g. when people base decisions regarding past events that happened with them or people close to them). They point out that the underweighting of events based on experience may be related to a small sample of previous experience with that given rare event.

Regarding the effects of decisions based on experience, Krawczyk et al. (2017) found through their experiments that a previous personal impact of a rare event has a greater effect on the weighting of insurance decisions in comparison to previous impacts on other people (i.e., the effect of other people's experiences would be discounted in comparison to own personal experiences). Cai and Song (2013) showed experimentally that 
even "hypothetical experiences" (e.g. a risk and insurance game) might play a role in increasing insurance take-up. The study found that such hypothetical experiences could have a stronger effect on individuals than what they have experienced in real life. For instance, an actual disaster in a neighbouring village that happened in the previous year could be less effective, while a hypothetical experience could be more effective due to being a more recent and personal experience.

\subsection{Affection}

It is related to the difference in the perceived value of a loss due to the effects of emotions for a particular object or circumstance. Following Slovic et al. (2004), "affective responses occur rapidly and automatically", and thus, being a part of our experimental or intuitive system to comprehend risk, rather than our analytical system. Rottenstreich and Hsee (2001) distinguished how individuals face uncertain events based on their degree of affection, either by affect-poor events (with little to none emotional connection, usually based on purely monetary effects, e.g. a $\$ 100$ coupon to pay a phone bill) or by the affect-rich ones (with huge emotional attachment, it can also be related to money, but while linked to emotions, like a $\$ 100$ coupon for a fancy dinner or for a nice hotel at the beach). They showed experimentally (for instance by how much people would pay to avoid a monetary loss or to avoid an electric shock) how these events change the S-shaped degree of the probability weighting function from the prospect theory. It differs from a linear probability weighting function increasing in the probability estimation, with affect-rich events having a huge variation, greatly overweighting small probabilities, under-weighting big probabilities and with less sense of variation in intermediate probabilities.

Besides the impact of mental accounting, Hsee and Kunreuther (2000) found that affection plays a significant role in the perceived value of a loss. Individuals would be more impacted by the risk of experience loss related to objects, in which they are emotionally attached and will portray a higher demand for insurance compared to the same monetary expected loss for other objects or circumstances. Keller et al. (2006) is of the view that the effects of the availability heuristics are intensified by affection (when subjects received affect-rich images that evoke fear for instance). However, the effects could not be disentangled to explain which is the main factor that increases risk perception among individuals. Petrova et al. (2014) conducted a study replicating the experimental findings of Rottenstreich and Hsee (2001) in an insurance setting, with consistent overweighting of small probabilities. However, the study found inconsistent results for higher probabilities as well as insignificant results for underweighting. Traczyk and Fulawka (2016) found experimentally the S-shaped effect of affect-rich events in insurance decisions, but decisions of high numerate people (i.e. good ability to understand and process statistical information) were found to be unaltered by affection.

\section{A possible solution - The role of financial literacy}

The literature on insurance demand has found compelling motivations for its puzzles through behavioural biases, but it lacks insights on how to mitigate them and how to solve the insurance demand problems. Most of the behavioural biases discussed in the previous section have as their main outcome either wrong probability estimations or sub-optimal probability weighting. Thus, this may lead consumers for insurance decisions that result in either over or underinsurance. This section discusses the role of financial literacy in mitigating behavioural biases, as many individuals are fully or partially motivated by financial illiteracy $^{5}$ such as improper knowledge, habits, or usage of risks and financial technologies, such as insurance.

As from Huston (2010), financial literacy should be conceptualized into two dimensions. First dimension concerns understanding (knowledge) and second, on the use (application) of personal finance and financial concepts. In a similar way, OECD/INFE (2011) defines financial literacy as "a combination of awareness, knowledge, skill, attitude, and behaviour necessary to make sound financial decisions and ultimately achieve individual financial well-being". The non-proper understanding component of the definition may be due to either a lack of knowledge of how some financial technologies work or when uncomplicated statistical questions (numeracy) or simple financial concepts are hard to grasp. The necessary degree of ability to understand those concepts leads financial literacy to be closely attached to cognitive ability, as seen from evidence from Lusardi et al. (2010) and Finke et al. (2017).

Financial literacy was found to affect considerably the decision making of individuals, since the absence of it (i.e. financial illiteracy) might result in sub-optimal outcomes. This refers to lacking sufficient financial skills to understand or apply concepts and technologies of investment, banking or credit. From the survey from Lusardi and Mitchell (2014), the effect of financial illiteracy has been linked to poorer investment decisions, a greater chance of falling in financial fraud schemes are a result of lower financial management skills, lower participation in financial markets and lower commitment to retirement planning. Beyond this, financial illiteracy is also related to big social problems like over-indebtedness among consumers (Gathergood, 2012).

By its effects on decision making, it is only natural to see that financial literacy also has a significant impact on the insurance demand of individuals. In a study conducted on rainfall insurance in India, Cole et al. (2013) observed that villages with previous experience with insurance, higher financial literacy, and better ability to understand financial concepts had a greater demand for insurance. Bryan (2019), using a randomized controlled trial for partial agricultural insurance policies in Kenya and Malawi, found that the undertaking of insurance was highly linked to the literacy and knowledge of the product technology in the regions. Although, the causality of financial literacy to motivate financial behaviour may be hard to estimate for the possibility of endogeneity (since the attitude and use of financial concepts or technologies also make part of the financial literacy) good evidence attested the relation contouring the problem using strong instrumental variables. These instruments consisted of a number of newspapers and universities in regions of Russia (Klapper et al., 2012), and exposure to a new educational voucher in Chile (Behrman et al., 2012).

Not only financial literacy impacts insurance undertake, but it may also be a motivation behind many behavioural biases. Considering the biases and heuristics discussed, it can be clearly stated that most of them are motivated either by a lack of a proper understanding or by an inability to apply their financial knowledge into welfare optimal attitudes and behaviours. For instance, myopia and mental accounting are partially caused due to lack of knowledge. On the other hand, overconfidence and affection are biases that may lead to sub-optimal attitudes and behaviour, even for individuals with good knowledge. Thus, the improvement of one's financial literacy can also be a possibility to reduce the well-being of an individual and thereby, reducing the overall impact of behavioural biases in its decision-making process. Although, the literature has not reviewed causal studies

5 For a good overview of the topic, see De Beckker (2020). 
or studies for insurance demand, the correlation between multiple behavioural biases and financial literacy was verified among investors in stocks and mutual funds (Ateş et al., 2016; Jonsson et al., 2017).

One of the main treatments that can be used to help reduce biases and improve financial literacy degrees is financial education, which would aim at improving financial decision making and financial well-being ${ }^{6}$. From Kaiser and Menkhoff (2019) meta-analysis, financial education has a significant impact to financial knowledge and to a lesser extent financial behaviour. Altman (2012) argues that the gains of financial education to better decision making can be limited by the errors, biases and automated processes of our brain. He suggests as additional treatment a number of policies aiming at letting the better solutions for financial illiterate individuals easier to make (e.g. provide better quality information presented in a non-complex way; develop institutional environment favourable to good decisions with an incentive structure that internalize externalities involved in financial decision making). Besides, the author notes that financial education with a more practical and specific decisionmaking environment can also improve the financial decisions of individuals.

Although previous literature of financial literacy did not venture directly in the solution of behavioural bias in insurance demand, it had proposed possible improvements to the underinsurance problem through treatment that reduces financial illiteracy. Cole et al. (2013) showed through their field experiments that financial literacy materials improve the insurance demand of farmers against drought risk, having social spillover effects to farmers that have not received any material (which does not happen when farmers only receive discounts for insurance premiums and no financial literacy materials). Tennyson (2011) surveyed data pointed out low average for insurance financial literacy, with higher financial literacy related to people with previous financial education or interest in personal finance. Gaurav et al. (2011) experimentally showed the positive marketing effect of financial literacy for the demand for insurance against rainfall risk in India. Lin et al. (2017) evidently associated better financial literacy with more demand for life insurance, but does not consider the behavioural motivations for LPHC underinsurance. On the other hand, Lin et al. (2019) incorporated the idea of anchoring bias for insurance demand, that can be limited to better insurance literacy. However, the research was focused only on survey data, without analysing treatment effects nor considered other biases.

\section{Discussion and conclusion}

Using a comprehensive review of the literature, this study elucidates how behavioural biases explain the insurance demand puzzles, and how financial literacy might mitigate those biases. The study was instrumental in guiding how behavioural biases, as well as cognitive problems and heuristics, explain inconsistencies in insurance demand. In particular, the role on the insurance of coarse chance categories and the prospect theory framework; myopia and overconfidence; mental accounting and narrow framing; preference for protection against idiosyncratic risk; availability heuristics; underweight of decisions based on experience; and the effects of affection were discussed in brief. Insights from these behavioural economics frameworks have the following implications for insurance puzzles.

\footnotetext{
6 From OECD (2005), financial education can be defined as "the process by which financial consumers improve their understanding of financial products, concepts and risks and, through information, instruction and/or objective advice, develop the skills and confidence to become more aware of financial risks and opportunities, to make informed choices, to know where to go for help, and to take other effective actions to improve their financial well-being".
}

The implications of the prospect theory and coarse chance categories to the insurance demand literature have two degrees, based on antagonistic forces. First, depending on the value function and idiosyncratic reference points, loss-averse people could be less inclined to buy insurance for low probability events (negative side of value function), but be more inclined to buy it for medium and high probabilities events (positive side of value function). Second, considering their probability weighting function in comparison to what would be observed in the weight using the expected utility theory ${ }^{7}$, individuals would have a comparatively increased demand for insurance due to positive boost in the weighting of low probabilities that are suddenly seen as possible $^{8}$ ("possibility-effect"), with smaller comparative weight in medium probabilities. High probabilities seen as almost certain can also cause a comparative increase in insurance demand ("certainty effect"). Further research should compare empirically and experimentally, the antagonistic effects in terms of insurance demand for multiple risky events and degrees of loss aversion, estimating factors that trigger the possibility-effect as well as what indulge loss-averse people to consider insurance premiums as risky assets.

Although being different biases, myopic and overconfident people usually have similar underweighting of probabilities in their insurance decisions, resulting in underinsurance. But since their probability estimations are formed differently, further research can be conducted on investigating how treatment effects can be distinct for each of those biases. For instance, policies that share the real average threats of some risky event to the population could impact the probability estimation and weighting of myopic people but maybe ineffective to overconfident individuals, which may need more tailor-made advisory about their own risks.

Considering the implications of mental accounting and narrow framing to insurance, those two biases can easily shift the decisions of consumers. As in the example of insurance add-ons, in which the same account or frame mentality can make consumers buy extra premiums related to their existing plans. In regard to this, the same kind of mental framework can consider one risk in complete isolation to other risks (or even by not considering iterations of the same risk), reducing insurance demand. Research can dive further into how this mechanism works for individuals with those biases, searching what could trigger them to see multiple mental accounts or frameworks in interactions with each other.

In terms of impact towards the insurance market, the prevalence of availability heuristics tends to increase the probability weighting and the insurance demand of risky events that had a big impact in the community, vivid personal memories, plenty of media coverage or that happened recently. Future research should investigate the role of on-going campaigns of information (of threats, risks, and costs) about disasters in countries that suffer from underinsurance of LPHC risks while having a considerable prevalence of it.

The reliance to make decisions solely over experience might be one of the reasons for the underinsurance of low probability risks. Without sufficient knowledge of similar risky events happening inside their own community, consumers might be less inclined to buy insurance. As well as costly, the dependence on augmenting the time frame sample size of consumers to improve insurance

\footnotetext{
7 The expected utility theory weights probabilities as they were estimated since it does not consider a different probability weighting function like the prospect theory does.

8 We note that for low probabilities not seen as possible the effect would be the inverse, having a comparative decrease in the demand for insurance. Moreover, for finding those events highly improbable (in the "never going to happen" label), individuals would usually reject insurance premiums for them.
} 
demand is not enough, since many of those events have a low occurrence (e.g. once every ten or twenty years). The dissemination of description of events (either by media, public policies or companies) towards helping the underinsurance problem can also be harmful, since people that use description heuristics may over-insure beyond what is reasonable or of what they can afford. Further research in insurance demand should aim to investigate the thin line of the impact of description, looking for its benefits, costs, and limits.

The affection bias can be a double-edged sword towards insurance demand, which may cause over-insurance to events with big emotional connection, and underinsurance to events with none or low emotional connection. Although the insurance compensation for stolen objects with and without emotional attachment might be the same, the extra loss of losing the object with good childhood memories, for instance, may make people more eager to buy insurance premiums. As in the case of the availability heuristics, experimental and empirical research can verify if the impact of media can also transform affect-poor risky events in the face of the public into events with deep emotional connection, shifting insurance demand.

By focussing on the role of financial literacy in the insurance puzzle, the paper also provides routes for further research. In particular, the literature ignored the possibility to consider the behavioural biases and heuristics motivations for the insurance demand puzzles as issues arising from a certain degree of financial illiteracy. Financial literacy (i.e. the good knowledge and use of financial concepts and technologies) was found to have a significant role to play in decision making, with low levels of it (i.e. financial illiteracy) being linked with welfarereducing financial decisions (e.g. low commitment to retirement funds, poor investment decisions) and social problems (e.g. overindebtedness in society), with this also impacting insurance decision making. Although financial literacy improving measures were found in the literature to be able to reduce underinsurance, there are still no contributions to its effect on the behavioural biases of insurance puzzles. Since many biases and heuristics are motivated by either lack of knowledge or misuse of financial concepts and products (e.g. poor estimations of myopic people being motivated by lack of knowledge), it is natural to see the link with financial illiteracy, and measures that improve financial literacy could also end up mitigating behavioural biases that affect insurance demand. By this, the financial literacy approach can be seen as a possible new promising trend in the literature into solving the behavioural problem of insurance demand, which could promote better decisions and better financial outcomes to affected individuals.

The understanding of these behavioural motives, finding the root problems, as well as giving the right "remedies" to them can be a good way to approach the puzzles of insurance demand. In addition, the study strongly suggests that solving the personal finance knowledge and use issues that motivates many of those biases can be one of the main possible ways to mitigate the biases. For this purpose, the literature concerning financial literacy and education have much to add to answer the research questions of the insurance demand puzzles. The avenues of integrating those pieces of literature can certainly propose good fruits and developments to the insurance demand literature.

\section{References}

Altman, M., 2012. Implications of behavioural economics for financial literacy and public policy. J. Socioecon. 41 (5), 677-690.

Ateş, S., Coşkun, A., Şahin, M.A., Demircan, M.L., 2016. Impact of financial literacy on the behavioral biases of individual stock investors: Evidence from Borsa Istanbul. Bus. Econom. Res. J. 7 (3).

Barberis, N., 2013. The psychology of tail events: Progress and challenges. Amer. Econ. Rev. 103 (3), 611-616.
Behrman, J.R., Mitchell, O.S., Soo, C.K., Bravo, D., 2012. How financial literacy affects household wealth accumulation. Amer. Econ. Rev. 102 (3), 300-304.

Booij, A.S., Van de Kuilen, G., 2009. A parameter-free analysis of the utility of money for the general population under prospect theory. J. Econ. Psychol. 30 (4), 651-666.

Brown, J.R., Kling, J.R., Mullainathan, S., Wrobel, M.V., 2008. Why don't people insure late-life consumption? A framing explanation of the under-annuitization puzzle. Amer. Econ. Rev. 98 (2), 304-309.

Browne, M.J., Knoller, C., Richter, A., 2015. Behavioral bias and the demand for bicycle and flood insurance. J. Risk Uncertain. 50 (2), 141-160.

Bryan, G., 2019. Ambiguity aversion decreases the impact of partial insurance: Evidence from African farmers. J. Eur. Econom. Assoc. 17 (5), 1428-1469.

Burns, Z., Chiu, A., Wu, G., 2010. Overweighting of small probabilities. In: Wiley Encyclopedia of Operations Research and Management Science.

Cai, J., Song, C., 2013. Do Hypothetical Experiences Affect Real Financial Decisions? Evidence from Insurance Take-Up (No. 46862). University Library of Munich, Germany.

Clarke, D., Kalani, G., 2012. Microinsurance microinsurance decisions: decisions: evidence from evidence from Ethiopia. International Labour Office Geneva 19 (1), 1-38.

Cole, S., Giné, X., Tobacman, J., Topalova, P., Townsend, R., Vickery, J., 2013. Barriers to household risk management: Evidence from India. Am. Econ. J. Appl. Econ. 5 (1), 104-135.

Cremer, H., Roeder, K., 2013. Long-term care policy, myopia and redistribution. J. Public Econ. 108, 33-43.

Croson, R., Sundali, J., 2005. The gambler's fallacy and the hot hand: Empirical data from casinos. J. Risk Uncertain. 30 (3), 195-209.

De Beckker, K., 2020. Financial literacy uncovering avenues for future research. In: De Witte, K., Holz, O., De Beckker, K. (Eds.), Financial Education: Current Practices and Future Challenges. Waxmann Publishing, Münster, Germany.

De Donder, P., Leroux, M.L., 2013. Behavioral biases and long-term care insurance: a political economy approach. The BE J. Econ. Anal. Policy 14 (2), 551-575.

Finke, M.S., Howe, J.S., Huston, S.J., 2017. Old age and the decline in financial literacy. Manage. Sci. 63 (1), 213-230.

Galle, B.D., 2012. Myopia, Fiscal Federalism, and Unemployment Insurance: Time To Reform UI Financing. Boston College Law School Legal Studies Research Paper, p. 265.

Ganderton, P.T., Brookshire, D.S., McKee, M., Stewart, S., Thurston, H., 2000. Buying insurance for disaster-type risks: experimental evidence. J. Risk Uncertain. 20 (3), 271-289.

Gathergood, J., 2012. Self-control, financial literacy and consumer overindebtedness. J. Econ. Psychol. 33 (3), 590-602.

Gaurav, S., Cole, S., Tobacman, J., 2011. Marketing complex financial products in emerging markets: Evidence from rainfall insurance in India. J. Mark. Res. 48 (SPL), S150-S162.

Gottlieb, D., Mitchell, O.S., 2019. Narrow framing and long-term care insurance. J. Risk Insurance.

Harrison, G.W., Ng, J.M., 2019. Behavioral insurance and economic theory: A literature review. Risk Manag. Insur. Rev. 22 (2), 133-182.

Heger, M., Julca, A., Paddison, O., 2008. Analysing the Impact of Natural Hazards in Small Economies: The Caribbean Case (No. 2008/25). WIDER Research Paper.

Hertwig, R., Barron, G., Weber, E.U., Erev, I., 2004. Decisions from experience and the effect of rare events in risky choice. Psychol. Sci. 15 (8), 534-539.

Higgins, J.P., Green, S., 2011. Cochrane handbook for systematic reviews of interventions version. 5(0), 3

Hsee, C.K., Kunreuther, H.C., 2000. The affection effect in insurance decisions. J. Risk Uncertain. 20 (2), 141-159.

Huston, S.J., 2010. Measuring financial literacy. J. Consum. Aff. 44 (2), 296-316.

Hwang, I.D., 2016. Prospect Theory and Insurance Demand. Working Paper.

Jonsson, S., Söderberg, I.L., Wilhelmsson, M., 2017. An investigation of the impact of financial literacy, risk attitude, and saving motives on the attenuation of mutual fund investors' disposition bias. Manag. Finance.

Kaiser, T., Menkhoff, L., 2019. Financial education in schools: A meta-analysis of experimental studies. Econ. Educ. Rev. 101930.

Keller, C., Siegrist, M., Gutscher, H., 2006. The role of the affect and availability heuristics in risk communication. Risk Anal. 26 (3), 631-639.

Klapper, L., Lusardi, A., Panos, G.A., 2012. Financial Literacy and the Financial Crisis. The World Bank.

Krawczyk, M.W., Trautmann, S.T., van de Kuilen, G., 2017. Catastrophic risk: social influences on insurance decisions. Theory and Decision 82 (3), 309-326.

Kunreuther, H.C., Pauly, M.V., McMorrow, S., 2013. Insurance and Behavioral Economics: Improving Decisions in the Most Misunderstood Industry. Cambridge University Press.

Laury, S.K., McInnes, M.M., Swarthout, J.T., 2009. Insurance decisions for low-probability losses. J. Risk Uncertain. 39 (1), 17-44.

Lin, X., Bruhn, A., William, J., 2019. Extending financial literacy to insurance literacy: a survey approach. Account. Finance 59, 685-713. 
Lin, C., Hsiao, Y.J., Yeh, C.Y., 2017. Financial literacy, financial advisors, and information sources on demand for life insurance. Pac.-Basin Finance J. 43, 218-237.

Lusardi, A., Mitchell, O.S., 2014. The economic importance of financial literacy: Theory and evidence. J. Econ. Lit. 52 (1), 5-44.

Lusardi, A., Mitchell, O.S., Curto, V., 2010. Financial literacy among the young. J. Consum. Aff. 44 (2), 358-380.

Maskell, P., Malmberg, A., 2007. Myopia, knowledge development and cluster evolution. J. Econ. Geogr. 7 (5), 603-618.

OECD, 2005. Improving Financial Literacy: Analysis of Issues and Policies. OECD Publishing, Paris.

OECD/INFE, 2011. Measuring Financial Literacy: Questionnaire and Guidance Notes for Conducting an Internationally Comparable Survey of Financial Literacy. OECD Publishing, Paris.

Petrova, D.G., Van der Pligt, J., Garcia-Retamero, R., 2014. Feeling the numbers: On the interplay between risk, affect, and numeracy. J. Behav. Decis. Mak. 27 (3), 191-199.

Piaget, J., Inhelder, B., 1951. La Genèse de L'Idée de Hasard Chez L'enfant. Presses Universitaires de France.

Reyna, V.F., Brainerd, C.J., 2008. Numeracy, ratio bias, and denominator neglect in judgments of risk and probability. Learn. Individ. Differ. 18 (1), 89-107.

Richter, A., Schiller, J., Schlesinger, H., 2014. Behavioral insurance: Theory and experiments. J. Risk Uncertain. 48 (2), 85-96.

Rottenstreich, Y., Hsee, C.K., 2001. Money, kisses, and electric shocks: On the affective psychology of risk. Psychol. Sci. 12 (3), 185-190.

Samuelson, P.A., 1963. Risk and uncertainty: A fallacy of large numbers. Scientia $108-113$.

Schmidt, U., 2016. Insurance demand under prospect theory: A graphical analysis. J. Risk Insurance 83 (1), 77-89.
Schwarcz, D., 2010. Insurance demand anomalies and regulation. J. Consum. Aff. 44 (3), 557-577.

Slovic, P., Finucane, M.L., Peters, E., MacGregor, D.G., 2004. Risk as analysis and risk as feelings: Some thoughts about affect, reason, risk, and rationality. Risk Anal. Int. J. 24 (2), 311-322.

Slovic, P., Fischhoff, B., Lichtenstein, S., Corrigan, B., Combs, B., 1977. Preference for insuring against probable small losses: Insurance implications. J. Risk Insurance.

Tennyson, S., 2011. Consumers' insurance literacy: Evidence from survey data. Financial Serv. Rev. 20 (3), 165.

Thaler, R., 1985. Mental accounting and consumer choice. Mark. Sci. 4 (3), 199-214.

Traczyk, J., Fulawka, K., 2016. Numeracy moderates the influence of task-irrelevant affect on probability weighting. Cognition 151, 37-41.

Tversky, A., Kahneman, D., 1973. Availability: A heuristic for judging frequency and probability. Cogn. psychol. 5 (2), 207-232.

Tversky, A., Kahneman, D., 1979. Prospect theory: An analysis of decision under risk. Econometrica 47 (2), 263-291.

Tversky, A., Kahneman, D., 1981. The framing of decisions and the psychology of choice. Science 211 (4481), 453-458.

Tversky, A., Kahneman, D., 1986. Rational choice and the framing of decisions. J. Bus. 59 (4 pt 2).

Tversky, A., Kahneman, D., 1992. Advances in prospect theory: Cumulative representation of uncertainty. J. Risk Uncertain. 5 (4), 297-323.

Yin, H., Chen, J., Kunreuther, H., Michel-Kerjan, E., 2016. Availability Heuristic and Gambler's Fallacy over Time in a Natural Disaster Insurance Choice Setting. Working Paper. 